\title{
Tobacco smoking: the role of dental health professionals
}

Obehi O Osadolor ${ }^{1}$, Aisosa J Osadolor ${ }^{2}$, Uwaila Otakhoigbogie ${ }^{3}$ and Owens O Osadolor 4

1. Department of Child Dental Health, University of Nigeria Teaching Hospital, Ituku-ozalla, Enugu State. Nigeria.

2. Central Hospital, Oleh, Delta State, Nigeria.

3. Department of Oral Pathology \& Oral Medicine, University of Nigeria, Enugu State. Nigeria.

4. Edo Specialist Hospital, Benin City, Edo State, Nigeria.

Correspondence:

Osadolor 0.O.

osadolorobehi@yahoo.com

Submitted: June 2021

Accepted: August 2021

Published: November 2021
Citation: Osadolor et al, Tobacco smoking: the role of dental health. South Sudan Medical Journal 2021;14(4):132134 (C) 2021 The Author (s) License: This is an open access article under CC BY-NC DOI: https://dx.doi.org/10.4314/ssmj. v14i4.6

\begin{abstract}
Tobacco use is a serious public health problem with smoking as the most common method of consuming tobacco. It is a major preventable cause of premature morbidity and mortality. The prevalence of tobacco smoking varies from country to country. It creates a huge economic burden on the individuals who consume it and on the healthcare system. The current approach toward the management of tobacco smoking addiction revolves around a combination of education, counselling, and pharmacotherapy.

Dental professionals, such as dentists and dental therapists/hygienists have a special role in identifying smokers: odour and teeth stains are obvious revealing signs. Dentists are well placed in tobacco smoking cessation as they provide preventive and curative services on a regular basis. The regularity of visits by patients to dental clinics offer valuable contacts for dental health professionals to initiate and strengthen tobacco cessation measures. Dentists are in a unique position to motivate and assist their patients to quit tobacco use and smoking.
\end{abstract}

Keywords: Smoking, tobacco smoking, dental professionals

\section{Introduction}

Tobacco use is a serious public health problem with smoking as the most common method of consumption. Tobacco smoking is a major preventable cause of premature morbidity and mortality globally. ${ }^{[1]}$ It is a health threat to both the smokers themselves and the public arising from secondary exposure. It also poses a huge economic burden and financial implications ${ }^{[2]}$ on the individuals who consume tobacco and on the healthcare system. Tobacco forms of usage include cigarette, cigar, pipe, chewed tobacco, dipped tobacco, and snuff (moist and dry), but smoking is the most popular form of usage ahead of chewing tobacco, dipped tobacco, and snuff. Tobacco smoking is a learned behaviour resulting in a physical addiction to nicotine for many smokers.

Tobacco smoking in its various forms (cigars, cigarettes, pipes) is an important risk factor for many non-communicable diseases (NCDs) which include, but are not limited to, cardiovascular disease, lung disease, low birth weight and premature birth. ${ }^{[3]}$ It is a cause of many oral diseases and conditions, ranging from mild to life threatening, such as stained teeth, taste disturbance, halitosis, periodontal diseases, poor wound healing, oral mucosal lesions such as hairy tongue, smoker's melanosis (which is a discolouration of the oral mucosa), oral precancerous lesions, and oral cancers. ${ }^{[4]}$

\section{Prevalence of tobacco smoking}

Tobacco smoking often becomes addictive and the prevalence of smoking varies from country to country ${ }^{[5]}$ according to the following studies published in 2015 and 2018 from Africa. ${ }^{[6,7,8]}$ :

- The prevalence of tobacco smoking was $17.6 \%$ in South Africa. ${ }^{[6]}$

- From a systematic review in Nigeria, the prevalence of tobacco smoking was between $0.2 \%-32.5 \% .{ }^{[7]}$ 
- A rural population-based study in Tanzania reported a prevalence of current and ex-smokers of $5.4 \%$ and $19.8 \%$ respectively. ${ }^{[6]}$

- In Madagascar, the prevalence of cigarette smoking among adolescents was $19 \%{ }^{[6]}$

- In Uganda the prevalence of smoking was 34.4\% and $7.4 \%$ in men and women respectively. ${ }^{[6]}$

- The prevalence of tobacco use in Kenya was $19.1 \%$ and $4.5 \%$ among adult males and females respectively. ${ }^{[8]}$

- In Angola, the prevalence of current tobacco smoking was reported to be $6.1 \%{ }^{[6]}$

There might be a change in prevalence of tobacco smoking within the last three years in the countries reported.

\section{Smoking cessation programmes and the role of dental health professionals}

The habitual and addictive nature of tobacco smoking makes cessation difficult for chronic smokers. Guidelines suggest that smoking cessation interventions should include both behavioural support and pharmacotherapy ${ }^{[2]}$ (e.g., nicotine replacement therapy). The current approach to the management of tobacco smoking addiction revolves around a combination of education, counselling, and pharmacotherapy. ${ }^{[2]}$

The prevention and control of tobacco use are increasing issues of global importance. The links between tobacco use and some oral conditions create an opportunity for dental specialists to become involved in smoking cessation activities. Some dental treatment requires several visits, which provides further opportunities for initiation, fortification, and follow up of tobacco cessation measures. [9] These measures are aimed at reducing the effect of tobacco related morbidity and mortality ${ }^{[7]}$ by preventing the initiation of tobacco smoking by the non-users and cessation of tobacco smoking ${ }^{[9]}$ among current users and chronic smokers.

Dentists are well placed to contribute to tobacco smoking cessation as they provide preventive and curative services on a regular basis. ${ }^{[3]}$ Dental professionals can identify the people who use tobacco regularly, document their usage history and offer advice and written materials, as a part of their routine clinical practice. ${ }^{[10]}$ They can also adapt their clinical practice so that every patient who uses tobacco is identified and offered at least a session of brief counselling.

By expanding the dental examination, diagnosis, and treatment to include tobacco cessation, a potentially life-saving measure is added to an established service. ${ }^{[3]}$ Dentists have a special role in identifying smokers: odour and teeth stains are obvious revealing signs.

The dental clinic is an ideal setting for tobacco cessation services since preventive or treatment services, oral screening, and patient education have always been a large part of the dental practice. Counselling from a health professional such as a dentist is an effective method of helping patients quit the tobacco habit. The visits of patients to dental clinics or health centres where dental services are offered can create a valuable contact, ${ }^{[4]}$ for dental health professionals or allied dental health professional with adequate knowledge and training to initiate anti-smoking activity.

Sometimes, these dentist-patient contacts are underutilized and there is little interaction between dentist and his patient with regard to prevention of smoking and its consequences. ${ }^{[11]}$ It could be attributed to the lack of practice time and resistance on the part of the patients, so some dental professionals avoid this topic.

Enhancing motivation ${ }^{[12]}$ is an important part of the overall treatment for tobacco addiction as it increases smokers' enthusiasm, sense of purpose, and will to quit. Dental health professionals should try to advocate for the implementation of the World Health Organization $(\mathrm{WHO})^{[13]}$ framework convention in tobacco control in their locality of practice.

\section{Financial support and sponsorship: None}

Conflict of interest: None

\section{References}

1. Sujatha S, Iyengar A, Pruthvish S, Shivraj NS. Tobacco cessation practices among dental health professionals in Bengaluru city. J Int Oral Health 2015;7(10):28-32.

2. Manakil J, Miliankos A, Gray M, Itthagarun A, George R. Oral health and nicotine replacement therapy product. Eur J Gen Dent 2020;9:1-6.

3. Dedeke AA, Popoola OA, Adebiyi AO,Asuzu MC. Tobacco cessation services and related challenges among dentists in southwest Nigeria. Ann Ibd. Pg. Med 2018. 16(2):125-130.

4. Komar K, Glavina A, Boras VV, Verzak Z, Brailo V. Impact of Smoking on Oral Health: Knowledge and Attitudes of Dentists and Dental Students. Acta stomatol Croat. 2018;52(2):148155. https://doi.org/10.15644/asc52/2/8.

5. Brathwaite R, Addo J, Smeeth L, Lock K. A systematic review of tobacco smoking prevalence and description of tobacco control strategies in sub-Saharan African Countries; 2007 to 2014. PLoS ONE 2015; 10(7): e0132401. https://doi. org/10.1371/journal.pone.0132401. 
6. Magitta NF. Epidemiology of tobacco use and dependence in Sub-Saharan Africa: A systematic review. J Pulmonol Clin Res. 2018;2(1):9-15.

7. Oyewole BK, Animasahun VJ, Chapman HJ. Tobacco use in Nigerian youth: A systematic review. PLoS ONE 2018; 13(5):e

8. Gichuki JW, Opiyo R, Mugyenyi P, Namusisi K. Healthcare providers' level of involvement in provision of smoking cessation interventions in public health facilities. Kenya Journal of Public Health in Africa 2015; 6:523 https://doi. org/10.4081/jphia.2015.523

9. Bansala V, Guptab S, Chauhanc H, Katariad G, Nigame S, Bansalf V. Tobacco cessation practices among dental health professionals in Central India. IJIRDS 2017; 2(7):162 -167
10. Aluckal E, Kunnilathu A. Role of dental professionals in tobacco control. Int J Clin Dent Sci 2016;7:1-4.

11. Antal M, Forster A, Zalai Z, Barabás K, Ramseier C, Nagy K. Attitudes of Hungarian dental professionals to tobacco use and cessation. Cent Eur J Public Health 2012; 20 (1): 45-49

12. Roberts NJ, Kerr SM, Smith SMS. Behavioral interventions associated with smoking cessation in the treatment of tobacco use Health Services Insights 2013:6 79-85 https://doi.org/10.4137/ HSI.S11092

13. WHO Framework Convention on Tobacco Control. 2013 